\title{
Evaluation of the standard procedure for the treatment of periprosthetic joint infections (PJI) in Germany - results of a survey within the EndoCert initiative
}

Christina Rimke ${ }^{1 \dagger}$, Andreas Enz ${ }^{1 *+} \mathbb{D}$, Hermann Josef Bail ${ }^{2}$, Peter Heppt ${ }^{3}$, Bernd Kladny ${ }^{4}$, Gabriela von Lewinski ${ }^{5}$, Christoph H. Lohmann ${ }^{6}$, Katrin Osmanski-Zenk ${ }^{1}$, Holger Haas $^{7}$ and Wolfram Mittelmeier ${ }^{1}$

\begin{abstract}
Background: The periprosthetic joint infection (PJI) is a severe complication in the field of arthroplasty. Despite the rising number of primary joint replacements, no unified therapeutic standard has been established for the treatment of PJl yet.

Methods: A survey on the principles of treatment of PJI in Germany was conducted. A total of 515 EndoProthetikZentren (EPZ) were included, resulting in a response rate of $100 \%$.

Results: For early infections $97.6 \%$ of the centers use prosthesis-preserving procedures (DAIR). A one-stage exchange was implemented by less than $50 \%$ of the centers. If implemented, this treatment entails a prior selection of patients for a successful treatment. The two-stage exchange is performed in all centers, and most centers proceed with the implantation of a cemented spacer between stages. 75\% of the centers proceed with a center-based concept for the treatment of PJI.

Conclusion: The aim of a uniform PJl standard at the centers has not yet been fully achieved. Further improvements within the certification were initiated. The most relevant treatment options in Germany are displayed. The two-stage revision with a cemented spacer is the most widely implemented treatment. This exposition of principles could help for the further development of standardized treatment guidelines and definitions.
\end{abstract}

Keywords: Revision arthroplasty, Two-stage revision, Periprosthetic joint infection, Certification, Incident reporting, Surveys

\section{Background}

Joint replacement in end-stage joint diseases has been a well established and globally widespread surgical treatment method. Approximately 448.000 joint replacements are carried out in Germany every year [1]. Periprothestic joint infection (PJI) may occur in $0.2-2 \%$ of primary joint arthroplasty and up to $9 \%$ in implantation of megaprotheses

\footnotetext{
* Correspondence: andreas.enz@med.uni-rostock.de

${ }^{+}$Christina Rimke and Andreas Enz contributed equally to this work.

'Orthopädische Klinik und Poliklinik, Universitätsmedizin Rostock, Doberaner Straße 142, 18059 Rostock, Germany

Full list of author information is available at the end of the article
}

[2-4]. Due to demographic change and an increased functional demand of patients, an increase in primary implantation of endoprostheses is expected and thus an increase in the absolute number of PJI [5-7]. In implant loosening, infection already represents one of the most frequent indication for revision surgery. Incidence rates are up to $30 \%$, in addition to loosening of aseptic prostheses [1, 8-10]. PJI are associated with challenging diagnostic and therapeutic procedures and is one of the most serious complications [7, 11, 12]. Embedded in biofilm, bacteria show a better survival rate and a significantly worse accessibility for antibiotics [13]. Therefore, explantation of the prosthesis is required in

(c) The Author(s). 2020 Open Access This article is licensed under a Creative Commons Attribution 4.0 International License, which permits use, sharing, adaptation, distribution and reproduction in any medium or format, as long as you give appropriate credit to the original author(s) and the source, provide a link to the Creative Commons licence, and indicate if changes were made. The images or other third party material in this article are included in the article's Creative Commons licence, unless indicated otherwise in a credit line to the material. If material is not included in the article's Creative Commons licence and your intended use is not permitted by statutory regulation or exceeds the permitted use, you will need to obtain permission directly from the copyright holder. To view a copy of this licence, visit http://creativecommons.org/licenses/by/4.0/ The Creative Commons Public Domain Dedication waiver (http://creativecommons.org/publicdomain/zero/1.0/) applies to the data made available in this article, unless otherwise stated in a credit line to the data. 
many cases for successful treatment of PJI. Possible treatment methods for PJI include prosthesis-preserving procedures (DAIR) as well as one- and two-stage revision [11]. The optimal treatment procedure for PJI is often discussed $[11,14]$. To date, there is no internationally or nationally unified therapeutic standard for infected endoprostheses. The definition of such a therapy algorithm is crucial in order to guarantee successful treatment of PJI.

The EndoCert initiative was established in Germany in 2012 as the first worldwide certification system of medical centers for total joint replacement. The aim of this initiative is to maintain quality standards in primary and revision arthroplasties in large joints. The associated centers also develop and define standards as well as treatment processes, and they are subject to continuous re-certification $[15,16]$. In the present study, the standards for the treatment of PJI in all EndoCert arthroplasty centers in Germany were assessed. The therapy algorithms for one- or two-stage exchange, the duration of the two-stage interval, and the concepts of implant anchorage were analyzed. Potential differences in the treatment concepts between centers were identified and analyzed with respect to their numbers of endoprosthesis revision operation. The results of this study should lead to a harmonisation of the procedure for PJI within the EndoCert certification process.

\section{Method}

A questionnaire on the principles of treatment for PJI was developed in cooperation with the EndoCert Certification Commission. Questionnaires from all centers $(n=515)$ at the time of the survey (2015, recording years 2013-2014) were included in the evaluation (see supplementary file). The response rate of the survey was $100 \%$. More than half of the arthroplasty centers in Germany are affiliated with the EndoCert initiative. The centers are subdivided into $73 \%$ endoprosthesis centers (EPZ) with at least 100 interventions per year and $27 \%$ endoprosthesis centers of maximum care (EPZmax) performing at least 200 endoprosthesis interventions including at least 50 replacements of implants per year.

The questionnaire consists of five questions regarding therapeutic options for septic endoprosthesis replacement. The multiple-choice questions could be supplemented with further individual information by the center. Multiple answers were possible for certain questions. The feedback represented a self-declaration of standards of the centers, their present implementation is annually checked by random surveys within the framework of the audits.

\section{Statistics}

The data documentation and statistical evaluation of the collected data were carried out with Microsoft Excel
2013, version 15.0. The standard parameters of the descriptive statistics were determined and shown as absolute and percentage frequency. This is a complete survey since all of the centers which were certified at that time participated in the survey.

\section{Definition of periprosthetic joint infection}

Certified endoprosthesis centers are subject to a published PJI definition (MSIS [17], ICM [18], Trampuz [19], HICARE [20]). The diagnostic procedure is carried out in accordance with the definition.

\section{Ethics approval}

The study was approved by the local institutional ethical committee (A2015-0055).

\section{Results}

A total of 515 certified centers were included. $97.6 \%$ of these perform a procedure like debridement, antibiotics, and implant retention (DAIR) in case of an early infection. Only 3 centers do not follow this concept and nine centers left this question unanswered. Most centers (30.5\%) stated to perform DAIR up to 6 weeks after primary prosthesis implantation in case of early joint infections. $40.9 \%$ of the centers with more than 200 annual revisions choose this procedure up to a maximum of 4 weeks after implantation of the endoprosthesis, $50.4 \%$ of the centers use DAIR in an interval of 4-10 weeks. As part of the procedure $98.0 \%$ of the centers perform an exchange of the mobile parts of the implants.

If the DAIR procedure is not the appropriate treatment option, the one- and two-stage complete exchanges are carried out by the centers. All participating centers treating PJI use two-stage complete exchanges. However, only less than $50.0 \%$ of the centers regard the one-stage complete exchange as a possibility to treat PJI. The use of the one-stage exchange is predominantly implemented in individual cases (Table 1). The most relevant criteria for the centers to perform this procedure is the early infection (75\%) (Table 1). Regarding these results, it has to be considered that in $9.7 \%$ of the questionaries question number two was not correctly answered, the question in the related questionnaires was therefore not included in the evaluation.

All centers perform a two-stage complete exchange, but with different duration of the interval. The intermediate interval data ranged from 4 to 120 days and was divided into 4 groups (Fig. 1). The largest proportion of the centers choose an interval duration between 4 and 8 weeks. In addition, $90.0 \%$ of the centers use cement spacers during the intermediate interval. During the explantation procedure most centers $(58.4 \%)$ take 5 or more tissue samples for further diagnostics. 2 to 4 samples are taken by $37.9 \%$ of the centers, $3.7 \%$ take 1 
Table 1 Performance of the one-stage exchange in the hip and knee; conditions for the implementation of the procedure

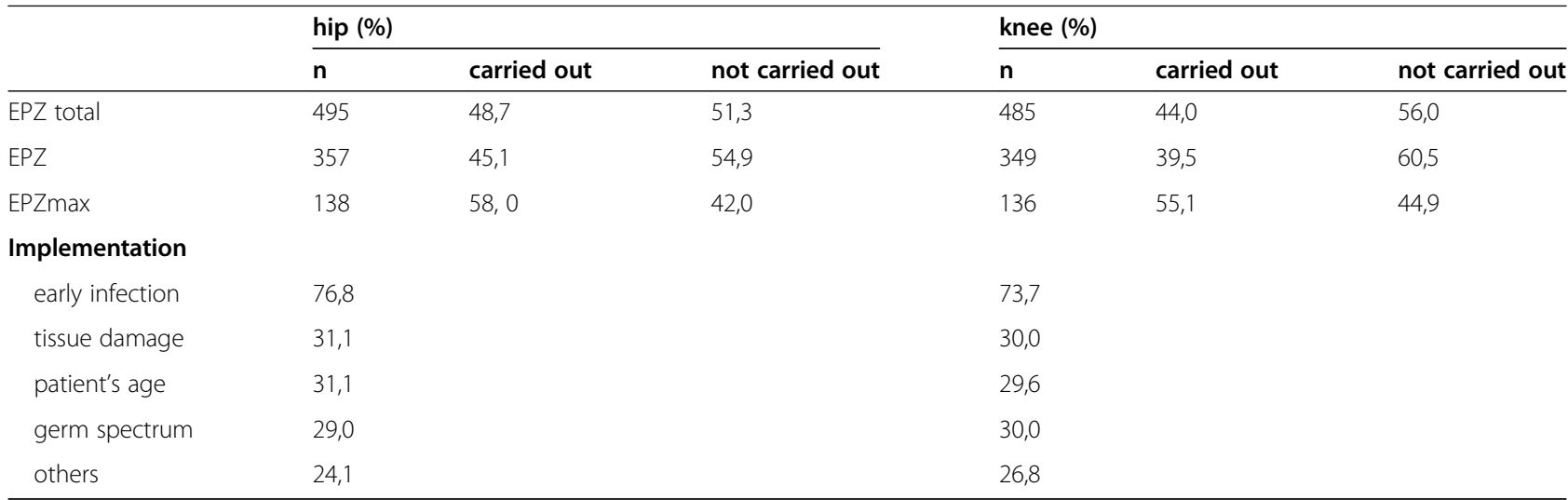

sample or did not specify their answer. Only half of the centers $(52.3 \%)$ take these samples from standardized localizations.

A further distinction between the one- and two-stage revisions was the final implant fixation (Fig. 2.). The centers that perform single-stage replacement in the knee almost entirely opt for cemented implant fixation in the knee (cementless 3.8\%, cemented 92.0\%). In contrast, for two-stage revision, these centers decide 10 times more in cementless implant fixation in the knee (cementless $44.1 \%$, cemented $54.4 \%$ ). For revisions procedures at the hip joint, the centers perform a cementless procedure (52.2\%) more often than a cemented procedure (46.8\%). When using a cemented fixation, $70.7 \%$ of the centers choose a prefabricated cement compared to $19.6 \%$ using an individually mixed type only.

Seventy-five point zero percent $(n=384)$ of the hospitals follow a specific concept to treat PJI (Table 2). This question was not answered by 16 centers (3.0\%).

Centers with a low number of annual revision surgeries apparently use preset algorithms less frequently. Hospitals with more than 200 exchange operations per year have reproducible standards for the treatment of PJI - twice as much than those with less than 50 exchange operations per year.

The results for the type of diagnostic are shown in Table 2. Especially large centers make use of microbiological and histological diagnostics before re-implantation more frequently than the total of all centers.

A standard of additional antibiotic therapy is used only in $59.1 \%$ of the centers after explantation and only $47.3 \%$ after insertion of new implants (Fig. 3). After explantation 86.0\% hospitals apply antibiotics over 4-6 weeks, while after reimplantation the duration is more inhomogeneous.

\section{Discussion}

The aim of this study was to present the current status of algorithms for the treatment of PJI in certified arthroplasty centers. All german centers certified by EndoCert have been included. These 515 centers are representing the most of the high-volume arthroplasty centers regarding the THR's and TKR's including the respective revisions [1, 15]. All EndoCert approved centers are obliged to send their implant data of primary and revision procedures to the German joint register EPRD. When comparing the register data with the knowledge of center-specific

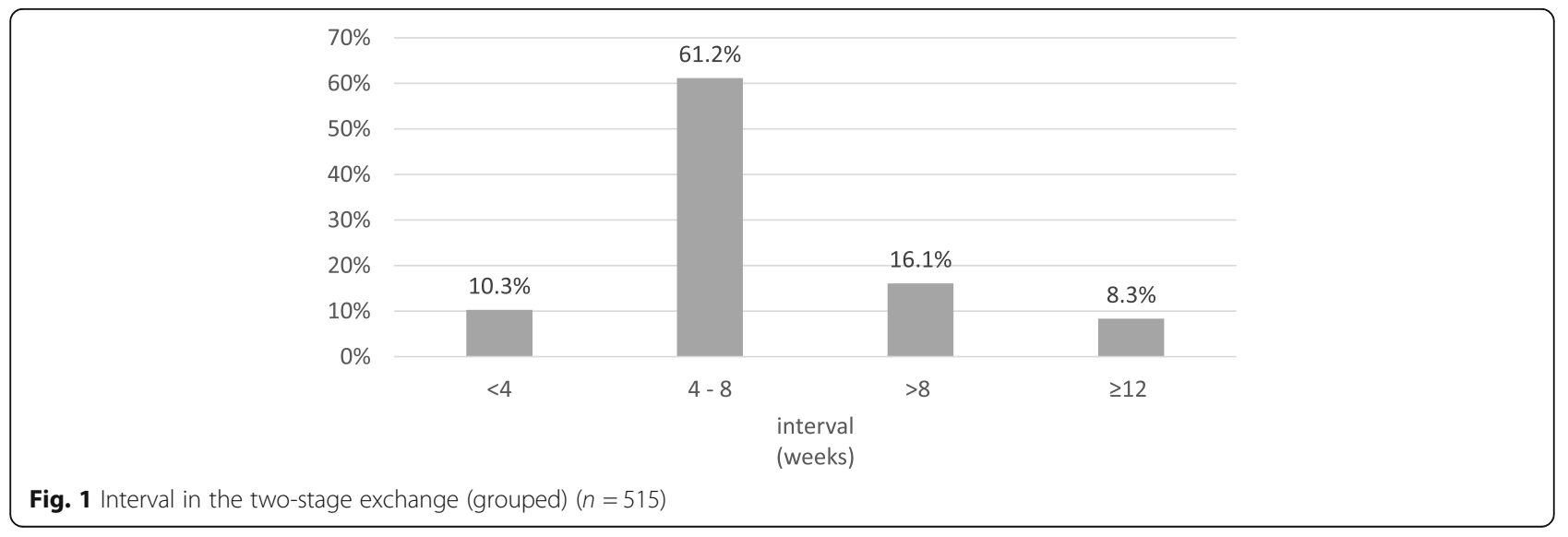




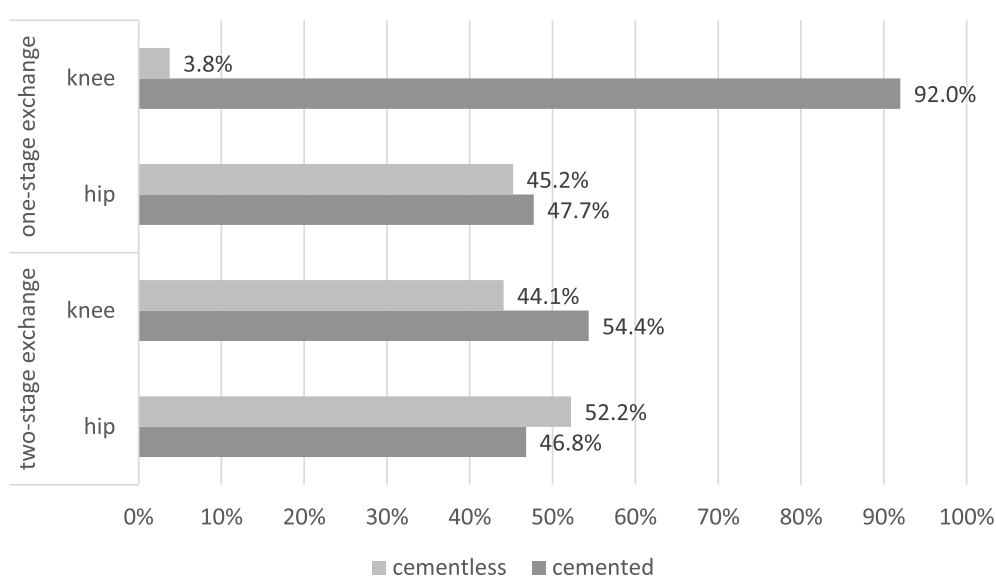

Fig. 2 Choice of implant fixation in one- and two-stage exchange for re-implantation (one-stage exchange: hip: $n=241$; knee: $n=213$; two-stage exchange: hip: $n=515$; knee: $n=515$ )

algorithms, these results may offer successful approaches for the treatment of PJI in the future. This is one of the few and one of the most comprehensive national studies on treatment of PJI [21-23].

The response rate of the survey questionnaires was $100 \%$. Only question two was not fully evaluable with 90.3\% and did not reach the maximum overall level; all other questions were answered with a $100 \%$ evaluable response rate.

In the registers, such as the Swedish Hip and Swedish Knee Arthroplasty Register (SHAR and SKAR $[24,25]$ ), the American Joint Replacement Registry (AJRR [26]), the Australian Orthopedic Association National Joint Replacement Registry (AOANJRR [27]), as well as in the German joint register (EPRD [28]), the term revision is not consistently defined. There is no definition if a revision is reported as implant-related or if it is considered infected. Infections are recorded as the cause of revisions but are not further discussed in detail. The change of inlays in the case of infections does not count as revision in the registers and is not further evaluated with respect to success or failure of the procedure; soft tissue surgery is not recorded in some cases either [25]. Only the SKAR addresses this problem in a separate section [25]. Revision procedures and algorithms are not recorded in any of the registers [24-26, 28].

Due to the lack of uniform therapy algorithms for the treatment of PJI, the selected procedure is often based on traditions, experience and preferences of the surgeon and the institution $[5,29]$. While standards in primary joint replacement must already be established at the time of the initial certification of the center, the goal of consistent, reproducible and clinically coordinated diagnostic and therapeutic processes in treatment of PJI has not yet been sufficiently achieved. There is a development towards standardization in the field of septic endoprosthetic cases, at least in the certified centers. The high number of centers $(n=115)$ without a defined therapy concept clearly illustrates the need of compulsory and approved standards. Within the complication

Table 2 Presence of a defined clinical concept and type of diagnostic before re-implantation differentiated by the annual number of exchanges performed in the center

\begin{tabular}{|c|c|c|c|c|c|}
\hline center-internal concept & $\begin{array}{l}\text { EPZ } \\
\text { (total) } \\
(n=515 ; \%) \\
\end{array}$ & $\begin{array}{l}<50 \\
\text { exchanges/year } \\
(n=293 ; \%)\end{array}$ & $\begin{array}{l}50-100 \\
\text { exchanges/year } \\
(n=138 ; \%)\end{array}$ & $\begin{array}{l}101-200 \\
\text { exchanges/year } \\
(n=61 ; \%)\end{array}$ & $\begin{array}{l}>200 \\
\text { exchanges/year } \\
(n=23 ; \%)\end{array}$ \\
\hline existing & 75,0 & 72,3 & 82,0 & 83,6 & 87,0 \\
\hline non-existing & 22,0 & 27,7 & 18,0 & 16,4 & 13,0 \\
\hline \multicolumn{6}{|c|}{ Type of diagnostic before reimplantation } \\
\hline none & 12,4 & 10,2 & 15,2 & 16,4 & 13,0 \\
\hline joint puncture & 61,0 & 60,1 & 61,6 & 65,6 & 56,5 \\
\hline microbiology & 23,1 & 29,4 & 13,8 & 18,0 & 13,0 \\
\hline microbiology \& histology & 36,7 & 36,5 & 37,0 & 36,1 & 39,1 \\
\hline no answer & 0,6 & 0,7 & 0,7 & 0,0 & 0,0 \\
\hline
\end{tabular}




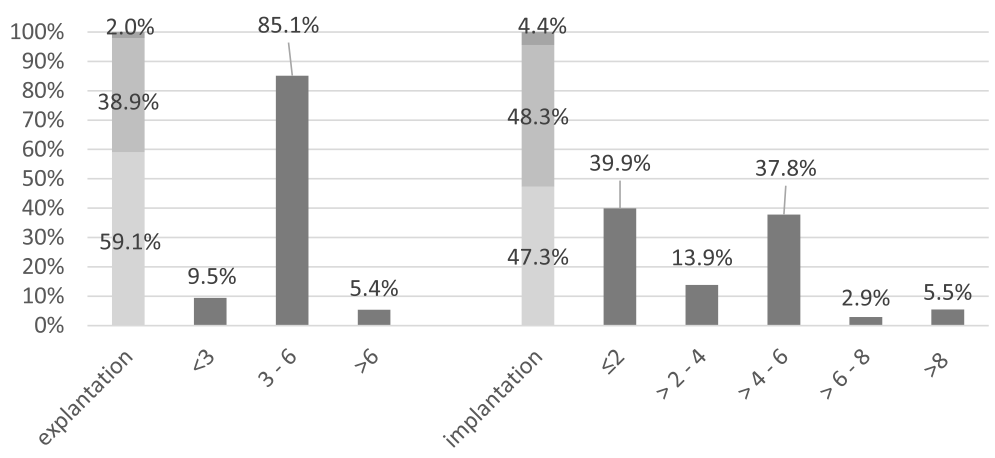

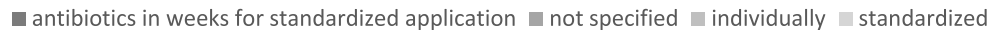

Fig. 3 Way of application of antibiotics after explantation and re-implantation; Duration of application of antibiotics in weeks for standardized application

management the EndoCert centers had to define an intraclinical treatment concept which is reviewed within the scope of regular audits. On an international and national level, this issue is of great importance [30] and a standardized approach is necessary when treating PJI.

This study showed that almost all EndoCert centers (97.6\%) use DAIR in early PJI. In addition to joint debridement, the replacement of modular prosthetic components is an essential part of the concept (98\%) in order to eradicate a potential source of infection and enable more extensive debridement [31]. A large number of centers stated that they would perform this procedure within 6 weeks after initial implantation while retaining the implant components that are well fixed in the bone. The literature states that after 6 weeks, the chance of success of implant-preserving surgery is reduced to $40 \%$ [32]. This is in agreement with the findings of implant-associated biofilm research showing that biofilm forms on the biomaterial surfaces early after implantation and is particularly advanced after 4 weeks [33, 34]. In centers with more than 200 revisions per year, partial replacement is used up to a maximum of 4 weeks, or in an interval of 4-10 weeks after primary implantation. The use of DAIR in cases of late hematogenous endoprosthesis infections, which can impress like an early infection with a fulminant course, was not considered in this survey, but represents a further treatment strategy.

In case that DAIR is not effective, all centers change their strategy to one- or two-stage revisions of all implant parts. The significance of both procedures in PJI is intensely discussed; some studies describe similar or higher success rates for one-stage revision [14, 35, 36]. Patient selection for eligibility of the procedure precedes the one-stage exchange. This is crucial for the success of the therapy [37-39]. The present study has shown that patient selection in the case of a one-stage revision is also of great significance for the EndoCert centers. The definition of early and late infection is not uniformly applied [11,31]. There is no clear statement on a duration regarded as early infection by the centers and the corresponding period to perform the one-stage exchange. In order to be able to determine uniform therapy algorithms, it is crucial to define early infection. The onestage exchange is only conducted at half of the EPZ for single cases and is not regarded as a $100 \%$ equivalent alternative to the two-stage procedure.

The two-stage exchange is implemented in $100 \%$ of the EPZ in Germany. This procedure can be applied to a wider range of patients and leads more reliably to successful treatment of the infection, especially in cases with difficult-to-treat bacteria $[20,40]$. Shorter OR time, the possibility of fractional expansion, management of the infection situation, the systematic administration of appropriate antibiotics both intravenously and locally with antibiotic-reinforced spacers, and an interval to reduce the risk of infection persistence prior to reinstallation result in an increased use in the EPZ. In cases of severe infections, poor soft tissue conditions or (partially) resistant bacteria, the literature reports a clear advantage of a two-stage procedure [41]. A disadvantage is the repeated anesthesia and relatively limited mobility in the (spacer) interval. The duration of the implant-free interval is 4 to 8 weeks in $61 \%$ of the centers and corresponds to the reports in the literature [20, 29, 42, 43]. The advantage of the two-stage revision is the shorter duration of the individual procedures and the possibility of obtaining several delayed tissue samples from different areas of the wound region, resulting in early and better detection of infection and appropriate administration of antibiotics [20].

The duration of the implant-free interval showed a high discrepancy of the indicated durations of 4 days to 120 days; a further differentiation of the values could not be 
determined from the questionnaire. On average, the spacer was in place for 42 days before the next revision, corresponding to the time recommended in the literature [20, 42].

PMMA spacers containing antibiotics are used during the interim interval in more than $90 \%$ of the centers and the Girdlestone situation is also implemented in $23 \%$ of the centers as alternative solution. If PMMA is used, the hospitals applied individually shaped cement spacers (61\%) and pre-formed spacers (42\% of the centers). When inserted in the knee and hip, this spacer should increase mobility in the interim phase [44]. However, the cast spacer can only be used for minor bone defects, while individual spacers are adapted to the specific defects and can bridge larger distances and ensure the release of antibiotics in the overall defect [45]. It is discussed whether the movement of the spacer has favorable properties for the healing of the infection $[46,47]$.

In addition to surgical decontamination, the management of suitable antibiotics plays an important role in the treatment of infections. The duration of therapy as stated in the literature varies from 14 days to 3 months [20, 29, 42, 48]. A distinction between removal and replacement is advisable and is carried out by $94 \%$ of the centers. Two hundred eighty hospitals $(45.6 \%)$ choose an individual application of antibiotics. At the time of the survey, the rate of standardization was still very low, which could partly be due to the various literature. The duration of antibiotic treatment after removal of the prosthesis is largely homogeneous; $85 \%$ of the centers surveyed state a duration of 3 to 6 weeks and only $5 \%$ state a longer duration of treatment. In contrast, the centers are much more inconsistent after reimplantation. The majority (39.9\%) stated a duration of antibiotics of up to 2 weeks whereas $37.8 \%$ stated a duration of 4 to 6 weeks. Further prospective comparing studies are necessary to determine the best outcome of the treatment concepts. As the duration of the course of antibiotics increases, the antibiotic-associated rate of adverse side effects that pose a risk to the patient increases [49].

\section{Conclusion}

The rising number of primary joint replacements underlines the importance of developing standards and harmonized definitions for the treatment of PJI. These standards have not yet been fully achieved neither in Germany nor internationally. The most relevant treatment options in Germany are shown. The two-stage revision with cemented spacer is the preferred method in PJI treatment, one-stage revision is performed in the centers under strict indication and for selected patients.
This summary of principles could serve as a basis for the further development of standardized treatment guidelines and definitions.

\section{Supplementary information}

Supplementary information accompanies this paper at https://doi.org/10. 1186/s12891-020-03670-y.

Additional file 1. "Principles of treatment for septic endoprosthesis revisions", endoCert Questionnaire for Principles of treatment for septic endoprosthesis revisions for the endoprosthetic centers.

\section{Abbreviations}

AOANJRR: Australian Orthopedic Association National Joint Replacement Registry; AJRR: American Joint Replacement Registry; DAIR: Debridement, antibiotics, irrigation, and retention of the prosthesis;

EPRD: Endoprothesenregister Deutschland (German joint register); EPZ: Endoprosthesis centers; EPZmax: Endoprosthesis centers of maximum care; OR: Operating room; PJI: Periprothestic joint infection;

PMMA: Polymethylmethacrylat; SHAR: Swedish Hip Arthroplasty Register; SKAR: Swedish Knee Arthroplasty Register

\section{Acknowledgements}

None.

\section{Authors' contributions}

$\mathrm{RC}, \mathrm{KOZ}, \mathrm{AE}, \mathrm{WM}$ : were responsible for data collection, analysis and interpretation of data, design of the work and revision. $R C, A E, H J B, P H, B K$, $\mathrm{GVL}, \mathrm{CHL}, \mathrm{KOZ}, \mathrm{HH}, \mathrm{WM}$ were responsible for data collection and revision. $\mathrm{RC}, \mathrm{AE}, \mathrm{HJB}, \mathrm{PH}, \mathrm{BK}, \mathrm{GVL}, \mathrm{CHL}, \mathrm{KOZ}, \mathrm{HH}, \mathrm{WM}$ approved the submitted version and agreed to be personally accountable for the author's own contributions and ensured that questions related to the accuracy or integrity of any part of the work, even ones in which the author was not personally involved, were appropriately investigated, resolved, and the resolution documented in the literature. $\mathrm{RC}, \mathrm{AE}, \mathrm{HJB}, \mathrm{PH}, \mathrm{BK}, \mathrm{GVL}, \mathrm{CHL}, \mathrm{KOZ}, \mathrm{HH}, \mathrm{WM}$ have read and approved the final version of the manuscript.

\section{Funding}

This research received no specific grant from any funding agency in the public, commercial, or not-for-profit sectors. Open Access funding enabled and organized by Projekt DEAL.

\section{Availability of data and materials}

The consent of EndoCert - an Institution of the german socitey of orthopaedics and orthopaedic surgery has been granted. The data was collected and evaluated within the scope of the EndoCert certification. The specially designed questionnaire and the data obtained are stored and available at EndoCert.

\section{Ethics approval and consent to participate}

The study was approved by ethical committee of the university medicine Rostock: "Ethikkommission an der Medizinischen Fakultät der Universität Rostock", Germany, Votum: A2015-0055. Due to the survey character of the study without patient data or intervention, consent was not necessary.

\section{Consent for publication}

Not Applicable.

\section{Competing interests}

H. J. Bail, P. Heppt, B. Kladny, G. v. Lewinski, C. H. Lohmann, H. Haas and W. Mittelmeier are voluntary members of the certification commission board of the EndoCert. K. Osmanski-Zenk is funded fulltime via a third party-funded project of EndoCert, which is the fully owned subsidiary of the German Society for Orthopaedics and Orthopaedic Surgery. Ch. Rimke and A. Enz declare that there is no conflict of interest.

\section{Author details}

1Orthopädische Klinik und Poliklinik, Universitätsmedizin Rostock, Doberaner Straße 142, 18059 Rostock, Germany. ${ }^{2}$ Klinik für Orthopädie und 
Unfallchirurgie, Klinikum Nürnberg Süd, Universitätsklinik der Paracelsus Medizinischen Privatuniversität Nürnberg, Breslauer Straße 201, 90471 Nuremberg, Germany. ${ }^{3}$ OCE Orthopädie Centrum Erlangen, Nägelsbachstraße 49A, 91052 Erlangen, Germany. ${ }^{4}$ M\&l Fachklinik Herzogenaurach, In der Reuth 1, 91074 Herzogenaurach, Germany. ${ }^{5}$ Klinik für Unfallchirurgie, Orthopädie und Plastische Chirurgie, Universitätsmedizin Göttingen, Robert-Koch-Straße 40, 37075 Goettingen, Germany. ${ }^{6}$ Orthopädische Universitätsklinik, Otto-von-Guericke Universität Magdeburg, Leipziger Str. 44, 39120 Magdeburg, Germany. ${ }^{7}$ Allgemeine Orthopädie, Unfallchirurgie und Sportmedizin, Gemeinschaftskrankenhaus St Elisabeth St Petrus St Johannes gGmbH, Haus St. Petrus / Bonner Talweg 4-6, 53113 Bonn, Germany.

Received: 19 June 2020 Accepted: 24 September 2020 Published online: 19 October 2020

\section{References}

1. Grimberg A, Jansson V, Liebs T, Melsheimer O, Steinbrück A. Endoprothesenregister Deutschland (EPRD) - Jahresbericht 2017 - Mit Sicherheit mehr Qualität. Berlin; 2018.

2. Otto-Lambertz C, Yagdiran A, Wallscheid F, Eysel P, Jung N. Periprosthetic infection in joint replacement. Dtsch Arztebl Int. 2017;114:347-53.

3. Kapadia BH, Berg RA, Daley JA, Fritz J, Bhave A, Mont MA. Periprosthetic joint infection. Lancet. 2016;387:386-94.

4. Trieb K, Heller K-D, Wirtz DC. Revisionsendoprothetik des Kniegelenks. 1. Aufl. Berlin Heidelberg New York: Springer-Verlag; 2011.

5. Castellani L, Daneman N, Mubareka S, Jenkinson R. Factors associated with choice and success of one- versus two-stage revision arthroplasty for infected hip and knee prostheses. HSS J. 2017;13:224-31.

6. Wengler A, Nimptsch U, Mansky T. Hip and knee replacement in Germany and the USA: analysis of individual inpatient data from German and US hospitals for the years 2005 to 2011. Dtsch Arztebl Int. 2014;111:407-16.

7. Kurtz SM, Ong KL, Schmier J, Mowat F, Saleh K, Dybvik E, et al. Future clinical and economic impact of revision total hip and knee arthroplasty. J Bone Joint Surg Am. 2007;89(Suppl 3):144-51.

8. Robertsson O, W-Dahl A, Lidgren L, Sundberg M. The Swedish knee arthroplasty register - annual report 2017. Helsingborg: Elvins Grafiska AB; 2017.

9. Kärrholm J, Lindahl H, Malchau H, Mohaddes M, Nemes S, Rogmark C, Rolfson O. The Swedish hip arthroplasty register - annual report 2016. Göteborg; 2016.

10. The NJR Editorial Board. 15th annual report 2018 England + Wales. National Joint Registry for England, Wales, Northern Ireland and the Isle of Man. 2018.

11. Zimmerli W, Ochsner PE. Management of infection associated with prosthetic joints. Infection. 2003;31:99-108.

12. Matthews PC, Berendt AR, McNally MA, Byren I. Diagnosis and management of prosthetic joint infection. BMJ. 2009;338:b1773.

13. Neut D, van der Mei HC, Bulstra SK, Busscher HJ. The role of small-colony variants in failure to diagnose and treat biofilm infections in orthopedics. Acta Orthop. 2007:78:299-308.

14. Leonard HAC, Liddle AD, Burke O, Murray DW, Pandit H. Single- or twostage revision for infected total hip arthroplasty? A systematic review of the literature. Clin Orthop Relat Res. 2014;472:1036-42.

15. Mittelmeier, W.; Bail, H. J.; Günther, K. P.; Heller, K. D.; Heppt, P.; Wirtz, D. C.; Haas, H. EndoCert ${ }^{-}$-Jahresbericht 2018. Zertifizierte EndoProthetikZentren gemäß EndoCert ${ }^{\oplus}$. Auditjahr 2017/Datengrundlage 2016. Online verfügbar unter https://www.clarcert.com/_Resources/Persistent/8ef51417e8466 9f90ebfde3f35adadc1a1562245/endocert-jahresbericht_2018-J2\%20\%281 80806\%29.pdf, zuletzt geprüft am 17.11.2018. 2018.

16. Haas H, Grifka J, Günther KP, Heller KD, Niethard FU, Windhagen $H$, et al, EndoCert ${ }^{\oplus}$. Zertifizierung von Endoprothetischen Versorgungszentren in Deutschland. Stuttgart: Georg Thieme; 2013.

17. Parvizi J, Tan TL, Goswami K, Hiquera C, Della Valle C, Chen AF, et al. The 2018 definition of periprosthetic hip and knee infection: an evidence-based and validated criteria. J Arthroplast. 2018;33:1309-1314.e2.

18. Parvizi J, Gehrke T. Proceedings of the second international consensus meeting on musculoskeletal infection; hip and knee section. Brooklandville: Data Trace Publishing Company; 2018.

19. Izakovicova P, Borens $O$, Trampuz A. Periprosthetic joint infection: current concepts and outlook. EFORT Open Rev. 2019;4:482-94.
20. Ellenrieder M, Lenz R, Haenle M, Bader R, Mittelmeier W. Two-stage revision of implant-associated infections after total hip and knee arthroplasty. GMS Krankenhhyg Interdiszip. 2011;6:Doc17.

21. Kuiper JWP, Vos S, Burger TJ, Colen S. Variety in diagnosis and treatment of periprosthetic joint infections in Belgium and the Netherlands. Acta Orthop Belg. 2016;82:149-60.

22. Moore AJ, Whitehouse MR, Gooberman-Hill R, Heddington J, Beswick AD, Blom AW, et al. A UK national survey of care pathways and support offered to patients receiving revision surgery for prosthetic joint infection in the highest volume NHS orthopaedic centres. Musculoskeletal Care. 2017;15: 379-85.

23. Anagnostakos K, Duchow L, Koch K. Two-stage protocol and spacer implantation in the treatment of destructive septic arthritis of the hip joint. Arch Orthop Trauma Surg. 2016;136:899-906.

24. Kärrholm J, Lindahl H, Malchau H, Mohaddes M, Nemes S, Rogmark C, Rolfson O. Swedish hip arthroplasty register annual report 2018; 2019.

25. Robertsson O, W-Dahl A, Lidgren L, Sundberg M. Annual report 2018 Swedish knee arthoplasty register; 2018

26. ANNUAL REPORT 2018 - American Joint Replacment Regestry AJRR.

27. Stephen Graves, Richard de Steiger, Peter Lewis, lan Harris, et al. ANNUAL REPORT 2018 - Australian Orthopaedic Association National Joint Replacement Registry (AOANOJRR).

28. Grimberg A, Jansson V, Melsheimer O, Steinbrück A. Jahresbericht 2019 Endoprothesenregister Deutschland (EPRD); 2019.

29. Trampuz A, Zimmerli W. Prosthetic joint infections: update in diagnosis and treatment. Swiss Med Wkly. 2005;135:243-51.

30. Diaz-Ledezma C, Higuera CA, Parvizi J. Success after treatment of periprosthetic joint infection: a Delphi-based international multidisciplinary consensus. Clin Orthop Relat Res. 2013:471:2374-82.

31. Tsukayama DT, Estrada R, Gustilo RB. Infection after total hip arthroplasty. A study of the treatment of one hundred and six infections. J Bone Joint Surg Am. 1996:78:512-23.

32. Romanò CL, Manzi G, Logoluso N, Romanò D. Value of debridement and irrigation for the treatment of peri-prosthetic infections. A systematic review. Hip Int. 2012;22(Suppl 8):S19-24.

33. Ramage G, Tunney MM, Patrick S, Gorman SP, Nixon JR. Formation of Propionibacterium acnes biofilms on orthopaedic biomaterials and their susceptibility to antimicrobials. Biomaterials. 2003;24:3221-7.

34. Gbejuade HO, Lovering AM, Webb JC. The role of microbial biofilms in prosthetic joint infections. Acta Orthop. 2015;86:147-58.

35. Oussedik SIS, Dodd MB, Haddad FS. Outcomes of revision total hip replacement for infection after grading according to a standard protocol. J Bone Joint Surg Br. 2010;92:1222-6.

36. Wolf CF, Gu NY, Doctor JN, Manner PA, Leopold SS. Comparison of one and two-stage revision of total hip arthroplasty complicated by infection: a Markov expected-utility decision analysis. J Bone Joint Surg Am. 2011;93: $631-9$.

37. Osmon DR, Berbari EF, Berendt AR, Lew D, Zimmerli W, Steckelberg JM, et al. Diagnosis and management of prosthetic joint infection: clinical practice guidelines by the Infectious Diseases Society of America. Clin Infect Dis. 2013;56:e1-25.

38. Mühlhofer HML, Schauwecker J, Banke IJ, von Eisenhart-Rothe R. Septic endoprosthesis exchange : preoperative diagnosis and reimplantation. Orthopade. 2015:44:946-51.

39. Gehrke T, Alijanipour P, Parvizi J. The management of an infected total knee arthroplasty. Bone Joint J. 2015;97-B(10 Suppl A):20-9.

40. McLawhorn AS, Nawabi DH, Ranawat AS. Management of resistant, atypical and culture-negative periprosthetic joint infections after hip and knee arthroplasty. Open Orthop J. 2016;10:615-32.

41. Parvizi J, Gehrke T, Chen AF. Proceedings of the international consensus on periprosthetic joint infection. Bone Joint J. 2013;95-B:1450-2.

42. Li C, Renz N, Trampuz A. Management of periprosthetic joint infection. Hip Pelvis. 2018;30:138-46.

43. Karczewski D, Winkler T, Renz N, Trampuz A, Lieb E, Perka C, et al. A standardized interdisciplinary algorithm for the treatment of prosthetic joint infections. Bone Joint J. 2019;101-B:132-9.

44. Charette RS, Melnic CM. Two-stage revision arthroplasty for the treatment of prosthetic joint infection. Curr Rev Musculoskelet Med. 2018;11:332-40.

45. Jacobs C, Christensen CP, Berend ME. Static and mobile antibioticimpregnated cement spacers for the management of prosthetic joint infection. J Am Acad Orthop Surg. 2009;17:356-68. 
46. Affatato S, Mattarozzi A, Taddei P, Robotti P, Soffiatti R, Sudanese A, et al. Investigations on the wear behaviour of the temporary PMMA-based hip Spacer-G. Proc Inst Mech Eng H. 2003;217:1-8.

47. Affatato S, Foroni F, Merola M, Baldacci F. Preliminary results of the tribological performance of new modular temporary knee spacer antibioticimpregnated. J Mech Behav Biomed Mater. 2019;95:205-9.

48. Anemüller R, Belden K, Brause B, Citak M, Del Pozo JL, Frommelt L, et al. Hip and knee section, treatment, antimicrobials: proceedings of international consensus on orthopedic infections. J Arthroplast. 2019;34:5463-75.

49. Tamma PD, Avdic E, Li DX, Dzintars K, Cosgrove SE. Association of adverse events with antibiotic use in hospitalized patients. JAMA Intern Med. 2017; 177:1308-15.

\section{Publisher's Note}

Springer Nature remains neutral with regard to jurisdictional claims in published maps and institutional affiliations.

Ready to submit your research? Choose BMC and benefit from:

- fast, convenient online submission

- thorough peer review by experienced researchers in your field

- rapid publication on acceptance

- support for research data, including large and complex data types

- gold Open Access which fosters wider collaboration and increased citations

- maximum visibility for your research: over $100 \mathrm{M}$ website views per year

At BMC, research is always in progress.

Learn more biomedcentral.com/submissions 